\title{
Relationship Between Vascular and Physical Function in Individuals with Peripheral Neuropathy
}

\author{
Arturo A. Arce-Esquivel, Brad Manor, Li Li and Michael A. Welsch*
}

Department of Kinesiology, Louisiana State University, Baton Rouge, LA, USA

\begin{abstract}
Background: Peripheral neuropathy is characterized by a reduction/alteration in sensation, muscle weakness and chronic fatigue, which may compromise physical function. Mechanisms contributing to the development of PN may include poor vascular function. The purpose was to examine the relationship between measures of vascular and physical function in individuals with peripheral neuropathy. Methods: This study used a cross sectional design to examine 59 individuals with peripheral neuropathy. Strain gauge plethysmography was used to assess lower leg vascular function. Specific measures included resting in-flow, venous outflow $\left(\mathrm{VO}_{\mathrm{t} 1 / 2}\right)$, and reactive hyperemic blood flow (RHBF). Physical function was examined using a 6-minute walk (6MWD), the timed up and go (TUG) test, and isokinetic knee extension (KE) and flexion (KF). Results: RHBF was related to the TUG $(r=-0.31, p=0.02)$ and $6 \mathrm{MWD}(\mathrm{r}=0.37, \mathrm{p}=0.007)$. Patients in the top tertile of the TUG had significantly higher peak RHBF compared to the lower tertiles. Those who walked $<400 \mathrm{~m}$ on the $6 \mathrm{MWD}$ had lower RHBF compared to those who walked $>400 \mathrm{~m}$. Finally, those in the top tertile of KF exhibited faster $\mathrm{VO}_{\mathrm{t} 1 / 2}$. Conclusions: These data indicate a relationship between vascular and physical function in peripheral neuropathy. Individuals with greater physical function exhibit more favorable measures of arterial inflow and venous outflow.
\end{abstract}

\section{BACKGROUND}

Peripheral neuropathies are a wide range of diseases affecting the peripheral nerves. According to the $108^{\text {th }}$ Congress report, 20 million Americans suffer from peripheral neuropathies [1]. In fact, peripheral neuropathy affects more people than several other well-publicized pathologies, including diabetes mellitus (17-18 million), coronary heart disease (13.2 million), and asthma (15 million) [2]. The prevalence of peripheral neuropathy increases significantly in older adults and nearly one-third of all diabetics suffer from this condition [1].

Irrespective of etiology, pathological changes associated with the disease are in many cases consistent with ischemia, secondary to vascular insufficiencies [3]. In fact, the literature has clearly established that chronic ischemia contributes to demyelination or axonal degeneration [4] which consequently, gives rise to a variety of symptoms including reduced or altered sensation, pain, muscle weakness, and chronic fatigue. The progression of peripheral neuropathy, generally, follows a distal to proximal pattern, with symptoms usually beginning in the toes before the fingers. Eventually, patients with peripheral neuropathy develop gait abnormalities and subsequent decrements in balance [5]. As a result, a large number of individuals with peripheral neuropathy suffer from a reduction in daily physical activity and reduced quality of life [6].

Interestingly, few studies have examined a possible link between vascular and physical function in peripheral neu-

*Address correspondence to this author at the Department of Kinesiology, Louisiana State University, Baton Rouge, LA, USA;

E-mail: mwelsch@1su.edu ropathy patients. In one such study, patients with peripheral arterial disease coupled with diabetes exhibited greater lower extremity dysfunction compared with peripheral arterial disease patients without diabetes. The apparent differences were, at least, in part secondary to poorer neuropathy scores [7]. More recently, a 2-year follow-up on individuals with peripheral arterial disease, identified baseline leg symptoms and ankle brachial index (ABI) as strong predictors of the degree of functional decline [8]. Furthermore, peripheral arterial disease patients reportedly have worse nerve conduction velocity in the legs, considered a clinical marker of peripheral neuropathy, than individuals without peripheral arterial disease [9], clearly suggesting a link between vascular deficiencies and neural function in those patients. Thus, it appears that vascular impairment contributes to the functional decline in patients with peripheral arterial disease.

Given the above-mentioned studies and evidence indicating neural deficiencies in patients with chronic ischemia, [4] and evidence of functional deterioration in patients with peripheral neuropathy $[10,11]$, the purpose of the present investigation was to examine the relationship between measures of vascular and physical function in individuals with peripheral neuropathy. We hypothesized that individuals with evidence of greater vascular function also would exhibit greater physical function among this population. Eventually, a greater understanding of those factors that contribute to a loss of functional ability and mobility in individuals with peripheral neuropathy may contribute to the development of strategies aimed at preserving independence and delay the onset of significant disability. 


\section{METHODS}

\section{Study Participants}

Individuals with physicians' diagnoses of peripheral neuropathy were recruited from the greater Baton Rouge metropolitan area to participate in this study. The inclusion criteria for the study were (a) ability to maintain an upright posture for at least one minute voluntarily; (b) ability to walk at least 20 yards independently; (c) willingness to participate in the study; and (d) a diagnoses of bilateral peripheral neuropathy. Individuals were excluded from participation if there was (a) a history or evidence of central nervous system dysfunction; (b) musculoskeletal deformity which could influence gait and balance; (c) a history or evidence of vestibular dysfunction; (d) a history of angina; (e) evidence of plantar ulcer; and (f) unstable disease (e.g. uncontrolled diabetes mellitus, arthritis, coronary artery disease, etc.). Following explanation of all the details of the study, each participant signed an informed consent approved by the Institutional Review Board.

\section{Experimental Design}

An observational prospective study was designed to examine the relationship between measures of vascular and physical function in individuals with peripheral neuropathy. Each participant was examined during two separate visits for the measurement of regional blood flow and physical function.

\section{Peripheral Sensory Testing}

Plantar cutaneous pressure sensitivity was assessed using the 5.07 gauge Semmes-Weinstein monofilament (North Coast Medical, Inc). The monofilament exerts $10 \mathrm{~g}$ of force at the tip upon buckling and has been used in both clinical and research settings. While there is no widespread consensus as to the optimal protocol, reduced sensitivity as measured by this monofilament has been correlated to common symptoms of peripheral neuropathy [12]. The fiber was applied to 5 sites on the plantar surface (i.e. the great and fifth toes, the first and fifth metatarsal, and the heel). The fiber was applied for $1.5 \mathrm{~s}$ and pushed to an angle of $90^{\circ}$. The order of the test sites was randomized to help prevent anticipation of the test by the participant. The participant indicated when he or she felt the fiber. In the presence of foot ulcers the testing sites were moved to the perimeter of the ulcer. All testing was performed by the same technician. Data was recorded as a " 0 " for no sensation, or a " 1 " if the monofilament was sensed.

\section{Vascular Assessment}

Vascular function of the lower leg was assessed using strain gauge plethysmography at rest and after 5 min of arterial occlusion. Specific measures included resting arterial inflow (AI), vascular capacitance and conductance, venous outflow volume and half time $\left(\mathrm{VO}_{\mathrm{t} 1 / 2}\right)$, and reactive hyperemic blood flow (RHBF).

Prior to the vascular assessments participants were instructed to refrain from food, alcohol or caffeine for $12 \mathrm{~h}$, and rigorous physical activity for $24 \mathrm{~h}$. Upon arrival to the vascular laboratory, the participants were placed on an ex- amination table and segmental pressure cuffs were positioned around the lower thigh and ankle [13]. In addition, a blood pressure cuff was positioned in the standard position around the upper arm to obtain blood pressure measures using an automatic blood pressure device (Datascope Accutorr 4, Datascope Corp. Paramus, NJ). Subsequently a mercuryfilled strain gauge was positioned around the widest girth of the lower leg. The position was marked and kept constant throughout the experiments. The strain gauge was connected to a plethysmograph (EC-5R system, Hokanson; Bellevue, WA). The leg was extended and slightly supinated and supported at least $10 \mathrm{~cm}$ above the level of the heart by foam blocks, but ensuring the strain gauge was not impeded, in order to provide the most comfortable arrangement for the participant. Following the set-up procedures, participants were allowed to rest for 25 minutes.

Resting in-flow was measured in triplicate as follows. First, foot circulation was occluded for 1 minute prior to the assessment by inflating the cuff at the ankle to $240 \mathrm{mmHg}$. Then, the segmental pressure cuff on the thigh was inflated to $7 \mathrm{mmHg}$ below diastolic blood pressure, measured at the arm. Arterial in-flow was then recorded three times for 10 seconds with 10 seconds between each recording.

Following an additional 2 minutes of maintaining the segmental thigh cuff at the previous determined pressure, venous capacitance was obtained. Subsequently, venous outflow was measured after release of the thigh pressure cuff for 20 seconds.

Patients were then given another 5 minutes of rest prior to initiating the hyperemic test. Following this rest period the thigh cuff was inflated to at least $60 \mathrm{mmHg}$ above systolic blood pressure for 5 minutes. In the fourth minute foot circulation was again occluded for 1 minute by inflating the cuff at the ankle to $240 \mathrm{mmHg}$. Upon release of the thigh pressure cuff to a pressure equal to $7 \mathrm{mmHg}$ below diastolic blood pressure, reactive hyperemic blood flow was measured in triplicate for 10 seconds, with 10 seconds between each measure.

Data were analyzed using a customized computer program (Matlab; Mathworks, Natick, MA, U.S.A.). Resting arterial in-flow was calculated from the entire slope, $10 \mathrm{sec}-$ onds in length, of the volume change over an interval of 10 seconds and the mean of three consecutive measurements was used to determine the average arterial in-flow. Recordings with significant movement artifact were excluded. Resting vascular resistance was calculated as mean arterial pressure / average in-flow. Resting vascular conductance was the reciprocal of vascular resistance or average in-flow / mean arterial pressure. For both assessments, vascular resistance and conductance, a blood pressure measure taken at that point was used for the analysis. Venous capacitance was determined through visual inspection of the position of the recording needle on the plethysmograph. Using a standard scale developed by the manufacturer an overlay is placed over the recording paper. The distance from the base of the graph to the position of the mark at the end of 2 minutes represents the relative venous capacitance.

Reactive hyperemic blood flow was calculated from the slope of the volume change over each 10 seconds interval. 
This allows for the determination of peak and the average reactive blood flow response across the three measurements.

To assess the timing characteristics of the venous outflow, venous outflow data were fitted to an exponential curve using the least mean square optimization method and processed by using Solver plug-in within the Microsoft Excel environment [14]. The Venous outflow half time $\left(\mathrm{VO}_{\mathrm{t} 1 / 2}\right)$ were calculated based on the time constant of the simulated exponential curve of each testing session.

\section{Physical Function Assessment}

On a separate day, participants were evaluated in a series of tests for physical function. At least five minutes of rest was provided in between each test, while at least two minutes of rest was provided between trials of applicable tests. The reliability of the functional testing protocol in this study has been reported elsewhere, and was found to be high for patients with peripheral neuropathy. The protocol used is outlined below.

A Six-Minute Walk test was administered using a standardized protocol outlined by the American Thoracic Society [15]. Briefly, cones were placed 30m apart along a well-lit indoor hallway. Participants walked as far as possible in 6min by walking back and forth around the cones. The distance covered was recorded to the nearest meter. Specific pre- and within-test participant instructions can be found in the American Thoracic Society statement [15]. Maximum walking distance traveled in 6 minutes (6MWD), to the nearest meter, was recorded and used for analysis.

In order to examine balance and coordination a timed upand-go test (TUG) was implemented, using a previously established protocol [16]. The TUG-test is a useful test in detecting mobility impairment [17]. Briefly, a firm chair with arm rests was placed in the middle of a well-lit, indoor hallway. In front of the chair, a distance of $3 \mathrm{~m}$ was marked on the floor and a large cone was placed on the opposite end from the chair. The test began with the participant seated with their back against the chair, arms in lap, and feet just behind the distance-marker on the floor. Instructions were to stand up using the arm rests if needed, walk safely to and around the cone, walk back to the chair, and sit all the way back in the chair as fast as possible. The timer was started on the work "go", and stopped when the participant's back touched the back of the chair. The average time to complete each of 2 separate trials was recorded and used for analysis.

Isokinetic knee extensor peak torque and knee flexor peak torque were measured with the Biodex isokinetic dynamometer (Biodex Medical, Shirley, New York). Participants sat in the Biodex chair with the back rest fixed at 85 degrees. Subjects were secured using pelvic and torso straps to minimize extraneous body movements that may influence testing performance. To further minimize such effects, participants were instructed to hold the Biodex handgrips during the procedure. The lateral femoral epicondyle was used as the reference point for matching the axis of rotation of the knee joint with that of the dynamometer resistance adapter. The lower limb was attached to the resistance adaptor to allow full knee extension and flexion to approximately 100 degrees.
A warm-up procedure consisting of five isokinetic knee extension and flexion movements at $60 \%$ s was initially completed. A 10 s rest period was given in between each trial. Participants were instructed to kick and pull their leg lightly during the first trial, and increase the amount of produced force with each trial so as to generate at or near maximal force during the fifth trial. Following a 3-min rest period, the maximal strength test was completed. Participants repeated warm-up procedures ( 5 trials, 10 s rest between trials), only with specific instructions to "push/pull your lower limb as hard as you can, remembering to breathe out normally during the trial." During all maximal trials, verbal encouragement and concurrent visual feedback from a computer monitor were provided to facilitate maximal values. Peak knee extension $(\mathrm{KE})$ and knee flexion $(\mathrm{KF})$ torque $(\mathrm{N} \cdot \mathrm{m})$ were recorded for each trial. Values from the three best trials for each movement were averaged and used for analysis.

\section{Statistical Analyses}

Statistical analyses were performed using SPSS for Windows (version 11.0). Data are presented as means and SD. To examine the associations between ages, measures of vascular and physical function, Pearson product moment correlation coefficients were calculated. Associations between the monofilament scores and various measures were examined using a Spearman rank correlation. To further appreciate the influence of the vascular indices on physical function, analyses of variance were used to compare participants classified according to tertiles on the performance scores, or in the case of the six minute walk test the clinically relevant score of $400 \mathrm{~m}$. Finally, potential differences in vascular and physical function based on certain groupings (e.g. etiology, gender, duration of disease) were determined using analyses of variance or independent t-tests. Significance was tested at the $95 \%$ confidence level $(p \leq 0.05)$.

\section{RESULTS}

\section{Participant Characteristics}

A total of 59 individuals with peripheral neuropathy participated in all aspects of this study. Participant characteristics are presented in Table 1. Forty-one percent of the participants were women, and $59 \%$ men. Seventy percent of the participants were over the age of 65 . The oldest participant tested was 87 years old, and the youngest was 39 years old. The duration of the diagnosis ranged from 6 months to 20 years, with $\sim 60 \%$ of the participants suffering from peripheral neuropathy less than 5 years. The etiology of peripheral neuropathy was Type II Diabetes Mellitus in approximately $36 \%$ of the subjects. In $7 \%$ of patients the etiology was chronic low back pain, and $5 \%$ of patients were cancer survivors. In the remaining subjects the etiology was not known. Thirty percent of the patients had a BMI greater than $30 \mathrm{~kg} \cdot \mathrm{m}^{-2}$, and $40 \%$ had stage I hypertension on the basis of systolic blood pressure ( $\mathrm{SBP}>130 \mathrm{mmHg})$.

\section{Peripheral Sensory Test}

The majority of patients reported partial sensation on the peripheral sensory tests. Ten percent of patients reported no sensation at any of the sites tested. The sites that yielded the 
Table 1. Participant Characteristics

\begin{tabular}{|c|c|c|c|c|}
\hline Age (yr) & 39 & 87 & 69 & 12 \\
\hline Height (m) & 1.5 & 2.0 & 1.7 & 0.1 \\
\hline Systolic Blood Pressure (mmHg) & 95 & 175 & 130 & 17 \\
\hline Diastolic Blood Pressure (mmHg) & 52 & 95 & 72 & 11 \\
\hline Resting Heart Rate (bpm) & 42 & 116 & 71 & 12 \\
\hline
\end{tabular}

$\mathrm{m}=$ meters; $\mathrm{kg}=$ kilograms; bpm=beats per minute.

greatest sensitivity were the big toe and fifth toe $(\sim 64 \%$ of participants reported sensing the monofilament). The site of the heel yielded the lowest sensitivity, with $\sim 16 \%$ of patients sensing the monofilament. The duration of disease was significantly associated with the sum of the scores on the peripheral sensory test $(r=-0.48, p=0.002)$.

\section{Vascular Assessment}

The average values for the blood flow indices at rest and following occlusion are presented in Table $\mathbf{2}$. The average resting inflow was $2.48 \pm 1.17 \mathrm{~mL} \cdot 100 \mathrm{~mL}^{-1} \cdot \mathrm{min}^{-1}$. Post occlusion reactive hyperemia values significantly decreased $(p=0.0001)$ with each measure from a peak hyperemic response of $26.93 \pm 13.44 \mathrm{~mL} \cdot 100 \mathrm{~mL}^{-1} \cdot \mathrm{min}^{-1}$, immediately after cuff release, to $17.23 \pm 8.58 \mathrm{~mL} \cdot 100 \mathrm{~mL}^{-1} \cdot \mathrm{min}^{-1}$ at the second and $13.72 \pm 7.59 \mathrm{~mL} \cdot 100 \mathrm{~mL}^{-1} \cdot \mathrm{min}^{-1}$ at the third time point. Group comparisons based on etiology, gender, or disease duration did not reveal significant differences in any of the blood flow indices, even when the diabetic patients were compared to all others. In addition, there were no correlations between age and any of the inflow measures. In contrast there was a significant association between age and $\mathrm{VO}_{\mathrm{t} 1 / 2}(\mathrm{r}=0.31, p=0.02)$. Finally, Table 3 reveals several significant associations between $\mathrm{RHBF}$, venous volume, $\mathrm{VO}_{\mathrm{t} 1 / 2}$ and vascular conductance.

\section{Physical Function Assessment}

The average scores for the physical function tests are shown in Table 4. No differences in performances scores were noted for the different etiologies and disease duration. Men were significantly stronger for KE (Men: 141 \pm 73 ; Women: $80 \pm 20 \mathrm{~N} \cdot \mathrm{m}, p=0.001$ ) and KF (Men: 70 \pm 30 ; Women: $39 \pm 10 \mathrm{~N} \cdot \mathrm{m}, p=0.001)$, but no differences were noted for the 6MWD and TUG. In addition, there were significant associations between age and each of the functional scores (Age vs. 6MWD: $\mathrm{r}=-0.34, \mathrm{p}=0.01$; Age $v s$. TUG: $\mathrm{r}=$ $0.33, \mathrm{p}=0.01$; Age $v s$. KE: $\mathrm{r}=0.51, \mathrm{p}=0.001$; and Age $v s . \mathrm{KF}$ : $\mathrm{r}=0.50, \mathrm{p}=0.001)$. Finally, Table 3 shows several associations between the performance scores. A particular strong association was noted between 6MWD and TUG $(r=0.79$, $\mathrm{p}=0.001$ ), whereas there were no significant relationships between TUG and measures of leg strength.

\section{Associations between Sensory Tests, Vascular and Physi- cal Function}

The associations between vascular indices and physical function are presented in Table 3. In particular the associations between peak RHBF responses and the TUG (Peak $\mathrm{RHBF}=37.88-1 * \mathrm{TUG} ; \mathrm{r}=-0.31, \mathrm{p}=0.024)$ and the 6MWD $($ Peak RHBF $=8.65+0.05 * 6 \mathrm{MWD} ; \mathrm{r}=0.37, \mathrm{p}=0.007)$ are of interest. Specifically, as shown in Fig. (1) individuals in the top tertiles of the TUG had significantly higher peak RHBF responses compared to the lowest tertile $[\leq 9.02 \mathrm{~s}$, RHBF: $30.97 \pm 12.56 \mathrm{~mL} \cdot 100 \mathrm{~mL}^{-1} \cdot \mathrm{min}^{-1} ; 9.02-10.88 \mathrm{~s}, \mathrm{RHBF}: 28.88 \pm$ $15.99 \mathrm{~mL} \cdot 100 \mathrm{~mL}^{-1} \cdot \mathrm{min}^{-1} ;>10.88 \mathrm{~s}$, RHBF: $19.88 \pm 8.10$ $\left.\mathrm{mL} \cdot 100 \mathrm{~mL}^{-1} \cdot \mathrm{min}^{-1}, \mathrm{p}=0.04\right]$. Those with a $6 \mathrm{MWD}$ score $<400 \mathrm{~m}$ had lower RHBF compared to those who walked $>400 \mathrm{~m}$ (see Fig. 2) $[<400 \mathrm{~m}$, RHBF: $23.47 \pm 10.52$ $\mathrm{mL} \cdot 100 \mathrm{~mL}^{-1} \cdot \mathrm{min}^{-1} ;>400 \mathrm{~m}$, RHBF: $30.65 \pm 15.05 \mathrm{~mL}$. $\left.100 \mathrm{~mL}^{-1} \cdot \mathrm{min}^{-1}, \mathrm{p}=0.05\right]$. In addition, peak vascular conductance was also significantly related to the TUG (Peak Vascular Conductance $=0.50-0.02 * \mathrm{TUG} ; \mathrm{r}=-0.38$, $\mathrm{p}=0.007$ ) and 6MWD (Peak Vascular Conductance $=0.50+$ $0.001 * 6 \mathrm{MWD} ; \mathrm{r}=0.44, \mathrm{p}=0.001)$, showing similar differentials based on the tertiles and $400 \mathrm{~m}$ threshold as for the peak RHBF response (see Figs. 3 and 4). Finally, a significant association between $\mathrm{VO}_{\mathrm{t} 1 / 2}$ and $\mathrm{KF}\left(\mathrm{VO}_{\mathrm{t} 1 / 2}=1.67-0.01 * \mathrm{KF}\right.$; $\mathrm{r}=-0.37, \mathrm{p}=0.01)$ and $\mathrm{KE}\left(\mathrm{VO}_{\mathrm{t} 1 / 2}=1.67-0.01 * \mathrm{KF} ; \mathrm{r}=-0.37\right.$, $\mathrm{p}=0.01)$ was observed, with those in the top tertile exhibiting faster $\mathrm{VO}_{\mathrm{t} 1 / 2}$ (see Fig. 5) [>77N·m, $\mathrm{VO}_{\mathrm{t} 1 / 2}: 1.01 \pm 0.31 \mathrm{~s} ; 36-$ $77 \mathrm{~N} \cdot \mathrm{m}, \quad \mathrm{VO}_{\mathrm{t} 1 / 2}: 1.54 \pm 0.64 \mathrm{~s} ;<36 \mathrm{~N} \cdot \mathrm{m}, \mathrm{VO}_{\mathrm{t} 1 / 2}: 1.38 \pm 0.40 \mathrm{~s}$, $\mathrm{p}=0.004]$. Finally, there were significant associations between vascular conductance $(r=0.44, p=0.01)$, the TUG $(r=-$ $0.37, \mathrm{p}=0.03$ ) and the sum of the sensory tests.

\section{DISCUSSION}

The purpose of the present investigation was to examine the relationship between measures of lower leg vascular and 
Table 2. Blood Flow Indices at Rest and Following Occlusion

\begin{tabular}{|c|c|c|c|c|}
\hline & Minimum & Maximum & Mean & SD \\
\hline Arterial Resting Inflow $\left(\mathrm{mL} \cdot 100 \mathrm{~mL}^{-1} \cdot \mathrm{min}^{-1}\right)$ & 0.96 & 6.29 & 2.48 & 1.17 \\
\hline Vascular Resistance (AU) & 13.46 & 109.85 & 45.43 & 22.01 \\
\hline Venous Capacitance $\left(\mathrm{mL} \cdot 100 \mathrm{~mL}^{-1} \cdot \mathrm{min}^{-1}\right)$ & 0.00 & 4.00 & 1.57 & 0.90 \\
\hline Venous Volume $\left(\mathrm{mL} \cdot 100 \mathrm{~mL}^{-1} \cdot \mathrm{min}^{-1}\right)$ & 8.00 & 58.00 & 31.26 & 12.37 \\
\hline $\mathrm{VO}_{\mathrm{t} 1 / 2}(\mathrm{~s})$ & 0.60 & 3.25 & 1.31 & 0.51 \\
\hline RHBF Peak $\left(\mathrm{mL} \cdot 100 \mathrm{~mL}^{-1} \cdot \mathrm{min}^{-1}\right)$ & 8.46 & 73.62 & 26.93 & 13.44 \\
\hline RHBF Average $\left(\mathrm{mL} \cdot 100 \mathrm{~mL}^{-1} \cdot \mathrm{min}^{-1}\right)$ & 7.52 & 51.18 & 19.36 & 8.58 \\
\hline $\begin{array}{l}\text { Peak Vascular Conductance } \\
\qquad\left(\mathrm{mL} \cdot 100 \mathrm{~mL}^{-1} \cdot \mathrm{min}^{-1}\right)\end{array}$ & 0.08 & 0.69 & 0.30 & 0.15 \\
\hline
\end{tabular}

$\mathrm{AU}=$ arbitrary units of resistance; $\mathrm{VO}_{\mathrm{t} 1 / 2}=$ venous outflow halftime; $\mathrm{s}=$ seconds; $\mathrm{RHBF}=$ reactive hyperemia blood flow.

Table 3. Correlations Between Vascularand Physical Function

\begin{tabular}{|c|c|c|c|c|c|c|c|c|c|c|c|}
\hline & 6MWD & TUG & $\mathbf{K E}$ & $\mathbf{K F}$ & $\begin{array}{l}\text { Venous } \\
\text { Cap }\end{array}$ & $\begin{array}{l}\text { Vasc } \\
\text { Con }\end{array}$ & $\begin{array}{l}\text { Venous } \\
\text { Vol }\end{array}$ & $\begin{array}{l}\text { Venous } \\
\text { Outflow }\end{array}$ & $\begin{array}{c}\text { RHBF } \\
\text { Avg }\end{array}$ & $\begin{array}{c}\text { RHBF } \\
\text { Peak }\end{array}$ & $\begin{array}{l}\text { Peak } \\
\text { Vasc } \\
\text { Con }\end{array}$ \\
\hline 6MWD (m) & 1 & & & & & & & & & & \\
\hline $\begin{array}{l}\text { TUG (s) } \\
\text { p-value }\end{array}$ & $\begin{array}{l}0.79 \\
0.001\end{array}$ & 1 & & & & & & & & & \\
\hline $\begin{array}{l}\text { KE (Trq) } \\
\text { p-value }\end{array}$ & $\begin{array}{l}0.29 \\
0.03\end{array}$ & $\begin{array}{r}-0.13 \\
0.32\end{array}$ & 1 & & & & & & & & \\
\hline $\begin{array}{l}\text { KF (Trq) } \\
\text { p-value }\end{array}$ & $\begin{array}{l}0.38 \\
0.004\end{array}$ & $\begin{array}{r}-0.23 \\
0.09\end{array}$ & $\begin{array}{l}0.89 \\
0.001\end{array}$ & 1 & & & & & & & \\
\hline $\begin{array}{l}\text { Venous Cap } \\
\text { p-value }\end{array}$ & $\begin{array}{l}0.01 \\
0.94\end{array}$ & $\begin{array}{l}0.11 \\
0.41\end{array}$ & $\begin{array}{l}0.27 \\
0.05\end{array}$ & $\begin{array}{l}0.24 \\
0.09\end{array}$ & 1 & & & & & & \\
\hline $\begin{array}{l}\text { Vasc Con } \\
\text { p-value }\end{array}$ & $\begin{array}{c}-0.28 \\
0.04\end{array}$ & $\begin{array}{l}0.30 \\
0.02\end{array}$ & $\begin{array}{l}0.07 \\
0.62\end{array}$ & $\begin{array}{l}0.03 \\
0.83\end{array}$ & $\begin{array}{l}0.44 \\
0.001\end{array}$ & 1 & & & & & \\
\hline $\begin{array}{l}\text { Venous Vol } \\
\text { p-value }\end{array}$ & $\begin{array}{l}0.04 \\
0.79\end{array}$ & $\begin{array}{l}0.03 \\
0.84\end{array}$ & $\begin{array}{l}0.29 \\
0.03\end{array}$ & $\begin{array}{l}0.34 \\
0.01\end{array}$ & $\begin{array}{l}0.71 \\
0.001\end{array}$ & $\begin{array}{c}0.53 \\
0.001\end{array}$ & 1 & & & & \\
\hline $\begin{array}{c}\text { Venous Outflow } \\
\text { p-value }\end{array}$ & $\begin{array}{c}-0.19 \\
0.18\end{array}$ & $\begin{array}{l}0.20 \\
0.14\end{array}$ & $\begin{array}{l}-0.28 \\
0.04\end{array}$ & $\begin{array}{r}-0.34 \\
0.01\end{array}$ & $\begin{array}{l}0.14 \\
0.32\end{array}$ & $\begin{array}{r}-0.02 \\
0.89\end{array}$ & $\begin{array}{l}0.13 \\
0.33\end{array}$ & 1 & & & \\
\hline $\begin{array}{c}\text { RHBF avg } \\
\text { p-value }\end{array}$ & $\begin{array}{l}0.16 \\
0.24\end{array}$ & $\begin{array}{r}-0.05 \\
0.75\end{array}$ & $\begin{array}{c}-0.01 \\
0.98\end{array}$ & $\begin{array}{r}-0.03 \\
0.85\end{array}$ & $\begin{array}{l}0.43 \\
0.002\end{array}$ & $\begin{array}{l}0.28 \\
0.04\end{array}$ & $\begin{array}{l}0.56 \\
0.001\end{array}$ & $\begin{array}{l}0.30 \\
0.03\end{array}$ & 1 & & \\
\hline $\begin{array}{l}\text { RHBF peak } \\
\text { p-value }\end{array}$ & $\begin{array}{c}0.37 \\
0.007\end{array}$ & $\begin{array}{r}-0.31 \\
0.02\end{array}$ & $\begin{array}{l}-0.06 \\
0.69\end{array}$ & $\begin{array}{r}-0.05 \\
0.71\end{array}$ & $\begin{array}{l}0.24 \\
0.09\end{array}$ & $\begin{array}{r}-0.01 \\
0.98\end{array}$ & $\begin{array}{l}0.39 \\
0.003\end{array}$ & $\begin{array}{l}0.23 \\
0.09\end{array}$ & $\begin{array}{l}0.88 \\
0.001\end{array}$ & 1 & \\
\hline $\begin{array}{c}\text { Peak Vasc Con } \\
\text { p-value }\end{array}$ & $\begin{array}{l}0.44 \\
0.001\end{array}$ & $\begin{array}{l}-0.38 \\
0.009\end{array}$ & $\begin{array}{r}-0.05 \\
0.78\end{array}$ & $\begin{array}{r}-0.08 \\
0.63\end{array}$ & $\begin{array}{c}-0.09 \\
0.59\end{array}$ & $\begin{array}{r}-0.10 \\
0.54\end{array}$ & $\begin{array}{l}0.56 \\
0.001\end{array}$ & $\begin{array}{l}0.25 \\
0.13\end{array}$ & $\begin{array}{l}0.78 \\
0.001\end{array}$ & $\begin{array}{l}0.93 \\
0.001\end{array}$ & \\
\hline
\end{tabular}

$6 \mathrm{MWD}=6$ minutes maximal walking distance; $\mathrm{m}=$ meters; $\mathrm{TUG}=$ timed up and go; $\mathrm{s}=\mathrm{seconds}$; $\mathrm{KE}=$ peak knee extension torque; $\mathrm{KF}=$ peak knee flexion torque, Venous $\mathrm{Cap}=\mathrm{venou}$ capacitance $\left(\mathrm{mL} \cdot 100 \mathrm{~mL}^{-1} \cdot \mathrm{min}^{-1}\right)$; Vas Con=vascular conductance $\left(\mathrm{mL} \cdot 100 \mathrm{~mL}^{-1} \cdot \mathrm{min}^{-1}\right)$, Venous Vol=venous volume $\left(\mathrm{mL}^{-100 \mathrm{~mL}}{ }^{-1} \cdot \mathrm{min}^{-1}\right)$; RHBF avg and RHBF peak=reactive hyperemia blood flow average and peak $\left(\mathrm{mL} \cdot 100 \mathrm{~mL}^{-1} \cdot \mathrm{min}^{-1}\right)$; Peak Vasc Con=peak vascular conductance $\left(\mathrm{mL} \cdot 100 \mathrm{~mL}^{-1} \cdot \mathrm{min}^{-1}\right)$.

physical function in individuals with peripheral neuropathy. The present data, indeed, support a link between measures of vascular and physical function in individuals with peripheral neuropathy. Specifically, individuals in the lowest tertile of the TUG and those with a $6 \mathrm{MWD}$ score $<400 \mathrm{~m}$ had signifi- cantly lower peak RHBF responses and peak vascular conductance compared to the other groups. In addition, individuals in the top tertile of $\mathrm{KE}$ and $\mathrm{KF}$ exhibited faster $\mathrm{VO}_{\mathrm{t} 1 / 2}$ than the other tertiles. These findings fit "The Disablement Pathway" developed by Verbrugge et al. [18] and suggest 
Table 4. Physical Function Scores

\begin{tabular}{|c|c|c|c|c|}
\hline & Minimum & Maximum & Mean & SD \\
\hline 6MWD (m) & 98 & 570 & 373 & 106 \\
\hline Timed up and go (s) & 6 & 33 & 11 & 4 \\
\hline $\mathrm{KE}(\mathrm{N} \cdot \mathrm{m})$ & 23 & 327 & 105 & 57 \\
\hline $\mathrm{KF}(\mathrm{N} \cdot \mathrm{m})$ & 10 & 152 & 51 & 25 \\
\hline
\end{tabular}

$6 \mathrm{MWD}=6$ minutes maximal walking distance; $\mathrm{m}=$ meters; $\mathrm{s}=\mathrm{seconds} ; \mathrm{KE}=\mathrm{knee}$ extension; $\mathrm{N} \cdot \mathrm{m}=$ newton-meter; $\mathrm{KF}=\mathrm{knee}$ flexion.

that physical function may, in part, be a consequence of deterioration of peripheral vascular function in individuals with peripheral neuropathy.

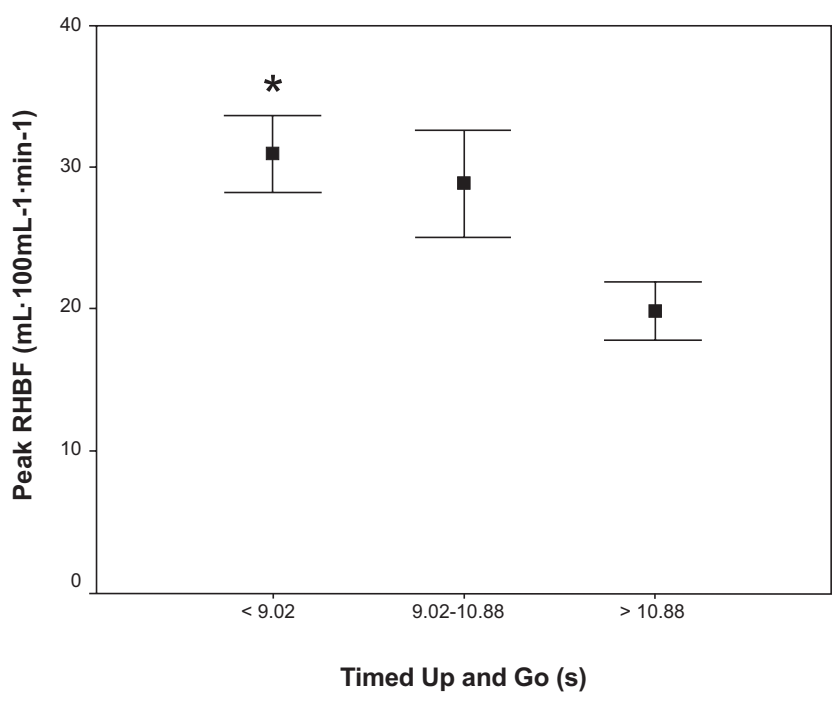

Fig. (1). Association between peak reactive hyperemia blood flow (peak RHBF) responses and the timed up and go (TUG) tertiles. * indicates significant difference from other tertiles $(\mathrm{p}=0.01)$.

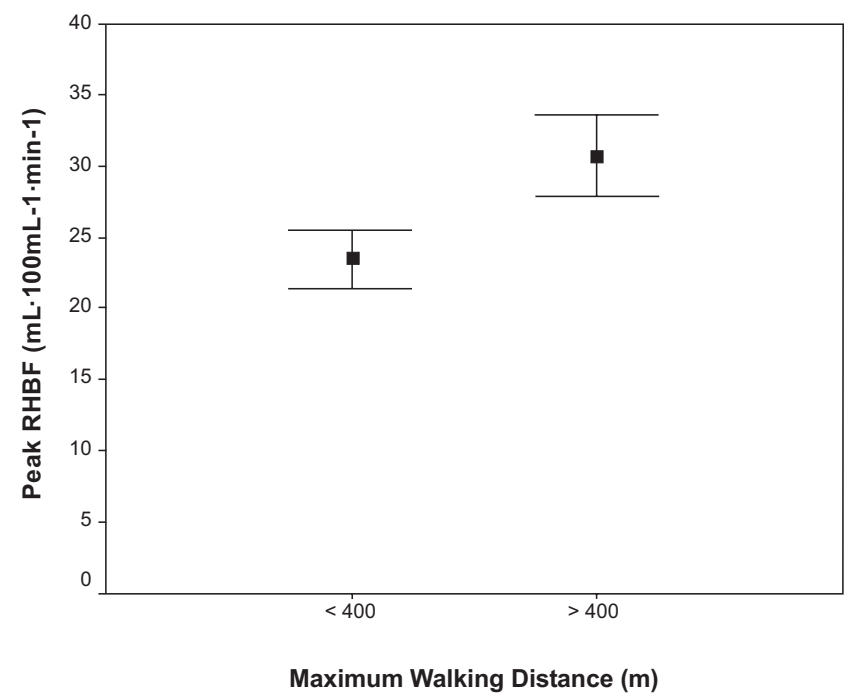

Fig. (2). Association between peak reactive hyperemia blood flow (peak RHBF) responses and the maximal walking distance cut-off points. Difference is significant at $\mathrm{p}=0.05$.

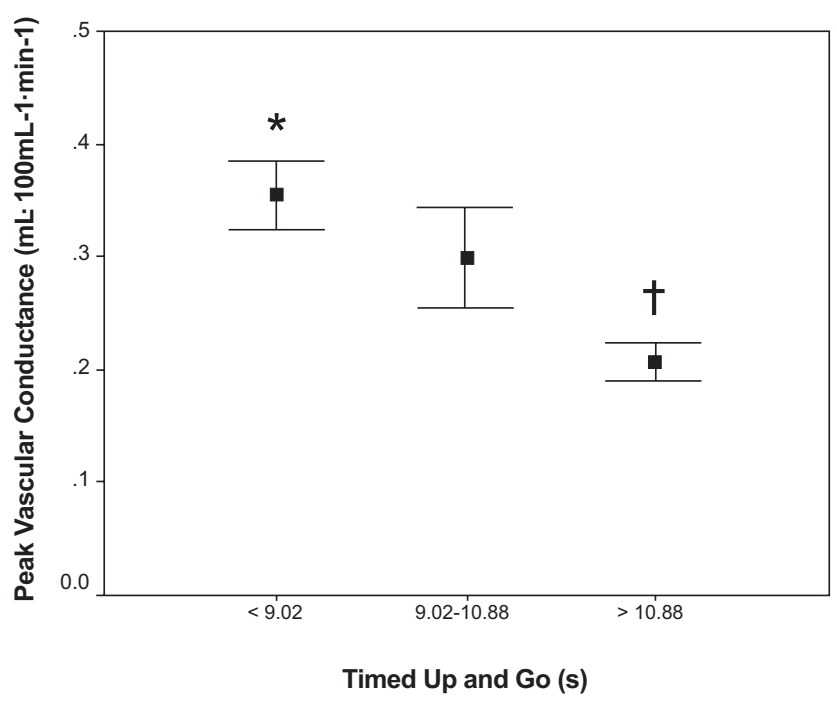

Fig. (3). Association between peak vascular conductance and the timed up and go (TUG) tertiles. * indicates significant difference from slowest tertile $(p=0.003)$. $\dagger$ indicates significant difference from middle tertile $(\mathrm{p}=0.05)$.

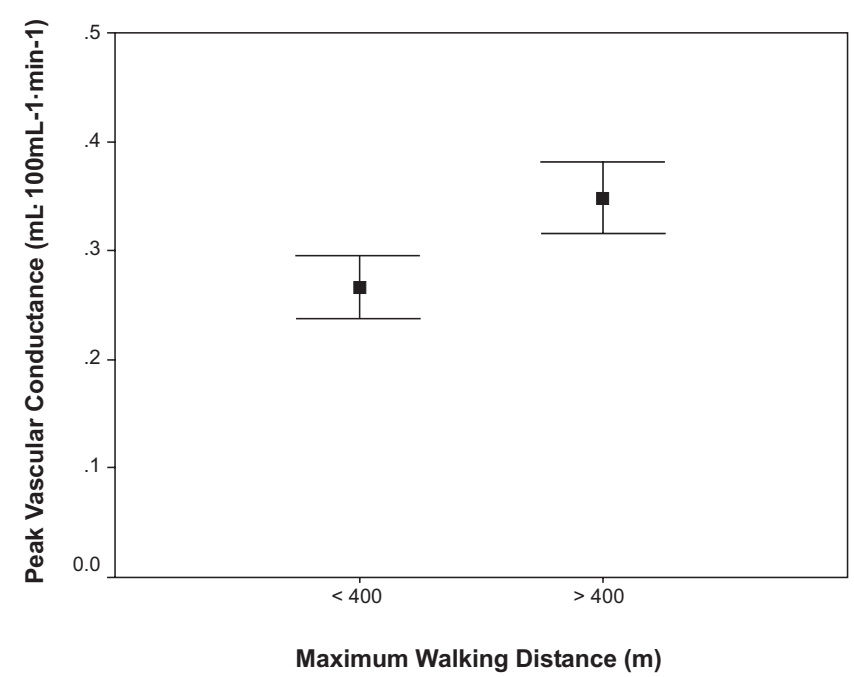

Fig. (4). Association between peak vascular conductance and the maximal walking distance cut-off points. Difference is significant at $\mathrm{p}=0.007$.

\section{Vascular Assessment}

The use of venous occlusion plethysmography is a powerful tool to study limb blood flow in humans. In general, the 
study of blood flow responses following occlusion indicates that younger, fitter, and healthier individuals exhibit greater flow responses, suggesting better vascular function. To that extent, peak RHBF responses in the present study were $\sim 17 \%$ lower than values reported for a group of healthy individuals in the same age range, and $\sim 18 \%$ and $29 \%$ higher than a group of heart failure and PAD patients, $[19,20]$ using the same analyses techniques. Although beyond the scope of this paper, a lower than expected peak RHBF response suggests alterations in the main factors that govern reactive hyperemia.

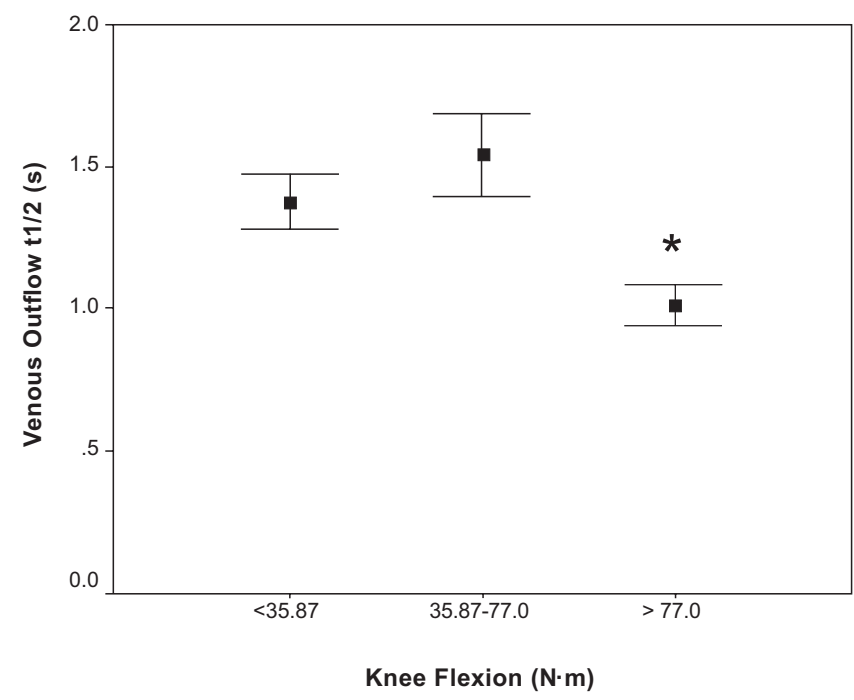

Fig. (5). Association between venous outflow halftime $\left(\mathrm{VOt}_{1 / 2}\right)$ and peak knee flexion torque $(\mathrm{KF})$ tertiles. * indicates significant difference from other tertiles $(\mathrm{p}<0.05)$.

More recently, researchers have also used peak limb vascular conductance immediately after a period of cuff arterial occlusion as an indirect measure of the structural limitations placed on limb muscle blood flow [21]. The values for peak vascular conductance, in the present study, were considerably lower than those reported for a group of men free of overt disease [21]. Thus, a lower than expected peak vascular conductance in these patients could reflect, in part, structural changes related to the arterial vasculature of the limbs (e.g. a reduction in vascular density and or number) that limit the extent of vasodilatation.

Together, these findings suggest that the arterial vasculature in individuals with peripheral neuropathy is compromised. Such a compromised system could certainly contribute to the progression of the disease. In fact, the literature provides significant evidence that conditions of acute and chronic ischemia contribute to changes in peripheral nerve function and structure [4]. In fact, Laghi Pasini et al. [4] reported a strong correlation between severity of nerve damage and stage of vascular insufficiency. It is not currently known what underlying mechanisms may contribute to deterioration of peripheral nerve function, but an increase in intracellular calcium [22], and/or oxygen species [23] could disrupt myelin and lead to axonal fiber degeneration.

In regards to venous circulation, several investigators have reported a reduction in venous function with advancing age [24] and in patients with heart failure [25]. It is not clear what mechanisms are involved in this reduced function, but impaired muscle activation and generalized deconditioning may be involved. In addition, it is important to consider the changes in the structure and function of the vasculature and peripheral nerves as a result of the aging process. In that regard, Fu et al. [24] reported an age-related decline in venous filling and emptying. It is not known if the progression of peripheral neuropathy may accelerate the decline in venous function, or if a decrease in venous function contributes to the progression of the disease. Given the important contribution of the venous system in metabolic waste removal and end-diastolic volume, changes in this part of the circulation may be quite significant in terms of overall cardiovascular function. The present data confirms an association between venous outflow half time and age in individuals with peripheral neuropathy.

\section{Physical Function Assessment}

A decline in functional performance in individuals with peripheral neuropathy is widely accepted, although the rate of decline and contributing mechanisms are much less understood. The six-minute walk test is an easily implemented test that determines the maximum distance a person can walk in 6-min. This test is a valid measure of "functional capacity" as it evaluates the integrated response of all systems involved during physical activity [15]. It is therefore frequently used in both elderly and diseased populations, and was therefore chosen for the current study. The total group average for the 6MWD $(373 \pm 106 \mathrm{~m})$ in this study appears to be quite typical for those seen in patients with heart failure, [26] indicating significant functional limitations. Importantly, based on the literature indicating that a walking distance less than $400 \mathrm{~m}$ is associated with higher prevalence of institutionalization, morbidity, mortality, hospitalization and transplantation [27], the results of the present study suggest $50 \%$ of the neuropathy patients are at elevated risk for complications.

The TUG test has been suggested to be a measure of basic mobility skills [16]. The test assesses the time it takes a participant to stand up from a chair, walk around a cone $3 \mathrm{~m}$ away, walk back to the chair, and sit down. Data regarding norms and threshold scores for the TUG-test are available but are somewhat conflicting. For example, Steffen et al. [28] reported average TUG-test times on a group of 60 to 69 years old men and women around $8 \mathrm{sec}$. Bischoff et al. [17] recommended the need for early evaluation and intervention for community-dwelling elderly women between $65-85$ years of age, who scored above $12 \mathrm{sec}$ on the TUG-test. Others identified a cutoff point of $24 \mathrm{sec}$ as a parameter that significantly predicted falls during a 6-month follow-up period. In the present study, $26 \%$ of participants scored above the $12 \mathrm{sec}$ mark, suggesting these patients may be at elevated risk.

Maximal isokinetic knee strength is a common measure of muscular strength and thus chosen for the current study. It has been shown to decline with advancing age [29, 30]. The average $\mathrm{KE}$ for this cohort $(104.71 \pm 56.83 \mathrm{~N} \cdot \mathrm{m})$ is approximately $10 \%$ lower than those reported for 60 to 69 year old individuals participating in NHANES 1999-2000 [30]. In 
addition, the average $\mathrm{KF}$ in the present study $(51.38 \pm 25.09$ $\mathrm{N} \cdot \mathrm{m}$ ) are $17 \%$ lower than those reported for men and women aged 70 to 79 years from the Health, Aging, and Body Composition Study [29]. These data suggest that patients with peripheral neuropathy have lower than expected leg strength. Lack of measurement of muscle mass, composition, or more sophisticated tests to examine neural recruitment, prevents speculation regarding the underlying mechanisms involved.

\section{Associations between Vascular and Physical Function}

The major focus of this paper was to examine the relationship between measures of lower leg vascular and physical function in individuals with peripheral neuropathy. The data are consistent with the stated hypothesis that individuals who have greater peak RHBF responses and vascular conductance following occlusion have higher scores on the TUG and 6MWD tests. In contrast, no significant associations were noted between the measures of vascular reactivity and knee flexion and extension.

It is important to notice the relationship between peak RHBF responses, vascular conductance and the 6MWD. Both vascular indices studied provide evidence of the ability of the vasculature to respond to an increase in metabolic demand (i.e. 5 minutes of occlusion). Arguably, the physiologic demands associated with the walking test would also serve to challenge the vasculature, and consequently individuals who have evidence of vascular impairments would have reduced physical function. Importantly, this study used $400 \mathrm{~m}$ as the differentiating point. Studies have indicated the prognostic value of this threshold as it relates to institutionalization, morbidity, mortality, hospitalization and transplantation [27]. It is interesting to speculate that the increased risk in patients with peripheral neuropathy, who score below $400 \mathrm{~m}$ on the walk test, may in part be secondary to diminished vascular function.

It is also important to notice the relationship between peak RHBF responses, vascular conductance and the TUGtest. The TUG-test is a basic test used to examine mobility and balance. Arguably performance of the TUG-test is a more complex interplay between physiological systems then the walk test. It is generally accepted that the TUG-test does not focus on independent effects of organ impairments, such as low muscle strength, decreased balance and other impairments, but measures the interaction of these factors on the performance of activities of daily living. It is not clear what influence a diminished vasculature has during the TUG-test in the peripheral neuropathy patients. However, we speculate that the initiation and subsequent continuation of a movement pattern is very much dependent on the ability to immediately increase blood flow to the working muscle. A major factor in the acute rise in muscle blood flow is the muscle pump, and subsequent distribution of cardiac output toward the working muscle. Thus, if the factors involved in the initial rise in blood flow with the onset of activity are impaired this could result in the increase time needed to perform the TUG-test. We are unaware of studies that have examined blood flow at the onset of exercise in peripheral neuropathy, but do recognize that such responses are blunted in the elderly. Thus, we encourage further studies to explore the link between muscle blood flow and functionality in the peripheral neuropathy patient.
The lack of significant associations between peak RHBF responses, vascular conductance and the isokinetic strength tests was not surprising. The strength tests probably are more specific in regards to the physiologic systems involved in the movement (e.g. muscle mass and neural innervations), and more than likely does not rely heavily on the delivery of blood to perform the test. In contrast, both $\mathrm{KE}$ and $\mathrm{KF}$ were significantly related to the $\mathrm{VO}_{\mathrm{t} 1 / 2}$. These findings further confirm data from our laboratory suggesting that muscular fitness is related to venous function [31]. The associations suggest the contribution of the venous system to physical function is beyond the typical role as a "passive volume reservoir". Importantly, the venous system is controlled primarily by the sympathetic nervous system. Generally, patients with chronic degenerative conditions tend to be hyperadrenergic. It is certainly possible that muscle deconditioning in some patients with peripheral neuropathy contributes to modifications in venous function.

We remain cautious in our interpretations considering the limitations inherent to a cross sectional design and the lack of causality presented. It is also recognized that the lack of longitudinal data regarding vascular and physical function and many other important factors in individuals with peripheral neuropathy are not accounted for in the present study. However, the present observations are unique in a sense that it is the first study to establish a link between vascular and physical function in patients with peripheral neuropathy, and consequently contributes to the existing literature in identifying several unique aspects that warrant further discussion and research.

It is also recognized that the present data do not elucidate possible mechanisms why individuals with the variables under interest are linked. The lack of a mechanistic approach in the current study prevents more sophisticated speculation regarding the development of possible preventive or compensatory interventions. However, given data indicating that exercise training can improve vascular function [32] we hypothesize that physical training may be an excellent way to preserve physical function and independence in certain patients with peripheral neuropathy.

In summary, the present findings strongly suggest that diminished vascular function contributes to a decrease in physical function in individuals with peripheral neuropathy. These findings are particularly interesting in light of recent data that clearly indicates that lower cardiorespiratory fitness is a significant predictor of dependence [33] and that $\mathrm{ABI}$ is a strong predictor of the degree of functional decline in patients with peripheral arterial disease [8]. It is our hope these data would stimulate clinicians to consider using vascular screening tools (e.g. measures of ABI, or blood flow) in patients with idiopathic peripheral neuropathy, in an effort to better understand patients' functional impairment.

The newly published "International Classification of Impairments, Disabilities, and Handicaps" (ICF) by the World Health Organization (www.who.int/classification/icf) emphasizes the influence of human body function and structure on the level of functioning, activity and participation. People with peripheral neuropathy, typically, do not perform a lot of physical activity due to their limitations, which in turn may have a negative effect on their quality of life. The recogni- 
tion of a relationship between vascular and physical function enables us to further investigate the mechanisms that underlie the functional limitations. These future studies may provide us the information necessary for the development of effective interventions.

\section{CONCLUSIONS}

In conclusion, the present investigation found significant relationships between measures of leg vascular and physical function in individuals with peripheral neuropathy. The results show individuals with greater physical function scores exhibited more favorable measures of arterial inflow and venous outflow. The lower physical function may, in part, be a consequence of deterioration of peripheral vascular function in individuals with peripheral neuropathy.

\section{AUTHORS' CONTRIBUTIONS}

AAAE: participated, coordinated and executed the study design, and drafted the manuscript.

BAD: assisted in the coordination and execution of the study design.

LL: assisted in the coordination of the study design, and drafting of the manuscript.

MAW: conceived of the study, and participated in its design and coordination and helped to draft the manuscript.

All authors read and approved the final manuscript.

\section{REFERENCES}

[1] CONGRESS US, Session TCd. Senate Report 108-35: Departments of Labor, Health and Human Srevices, and Education, and Related Agencies Appropriation Bill 2005.

[2] Thrall JH. Prevalence and costs of chronic disease in a health care system structured for treatment of acute illness. Radiology 2005; 235: 9-12.

[3] Krishnan AV, Lin CS, Kiernan MC. Nerve excitability properties in lower-limb motor axons: evidence for a length-dependent gradient. Muscle Nerve 2004; 29: 645-55.

[4] Laghi Pasini F, Pastorelli M, Beermann U, et al. Peripheral neuropathy associated with ischemic vascular disease of the lower limbs. Angiology 1996; 47: 569-77.

[5] Resnick HIM, Stansberry KB, Harris TB, et al. Diabetes, peripheral neuropathy, and old age disability. Muscle Nerve 2002; 25: 43-50.

[6] Guralnik JM, Ferrucci L, Simonsick EM, et al. Lower-extremity function in persons over the age of 70 years as a predictor of subsequent disability. N Engl J Med 1995; 332: 556-61.

[7] Dolan NC, Liu K, Criqui MH, et al. Peripheral artery disease, diabetes, and reduced lower extremity functioning. Diabetes Care 2002; 25: 113-20.

[8] McDermott MM, Liu K, Greenland P, et al. Functional decline in peripheral arterial disease: associations with the ankle brachial index and leg symptoms. JAMA 2004; 292: 453-61.

[9] Regensteiner JG, Wolfel EE, Brass EP, et al. Chronic changes in skeletal muscle histology and function in peripheral arterial disease. Circulation 1993; 87: 413-21.

[10] DeMott TK, Richardson JK, Thies SB, et al. Falls and gait characteristics among older persons with peripheral neuropathy. Am Phys Med Rehabil 2007; 86: 125-32.

[11] Richardson JK, Hurvitz EA. Peripheral neuropathy: a true risk factor for falls. J Gerontol 1995; 50: M211-5.
[12] Kamei N, Yamane K, Nakanishi S, et al. Effectiveness of SemmesWeinstein monofilament examination for diabetic peripheral neuropathy screening. J Diabetes Complicat 2005; 19: 47-53.

[13] Hopman MT, Groothuis JT, Flendrie M, et al. Increased vascular resistance in paralyzed legs after spinal cord injury is reversible by training. J Appl Physiol 2002; 93: 1966-72.

[14] Fylstra D, Lasdon L, Watson J, et al. Design and use of the microsoft excel solver. Informs Interfaces 1998; 28: 29-55.

[15] ATS Committee on Proficiency Standards for Clinical Pulmonary Function Laboratories. ATS statement: guidelines for the sixminute walk test. Am J Respir Crit Care Med 2002; 166: 111-7.

[16] Podsiadlo D, Richardson S. The timed "Up \& Go": a test of basic functional mobility for frail elderly persons. J Am Ger Soc 1991; 39: 142-8.

[17] Bischoff HA, Stahelin HB, Monsch AU, et al. Identifying a cut-off point for normal mobility: a comparison of the timed 'up and go' test in community-dwelling and institutionalised elderly women. Age Ageing 2003; 32: 315-20.

[18] Verbrugge LM, Jette AM. The disablement process. Soc Sci Med 1994; 38: 1-14

[19] Jondeau G, Katz SD, Toussaint JF, et al. Regional specificity of peak hyperemic response in patients with congestive heart failure: correlation with peak aerobic capacity. J Am Coll Cardiol 1993; 22 1399-402.

[20] Ogren M, Hedblad B, Engstrom G, et al. Leg blood flow and longterm cardiovascular prognosis in men with typical and atypical intermittent claudication. Eur J Vasc Endovasc Surg 2003; 26: 272-9.

[21] Proctor DN, Le KU, Ridout SJ. Age and regional specificity of peak limb vascular conductance in men. J Appl Physiol 2005; 98: 193202.

[22] Cheung JY, Bonventre JV, Malis CD, et al. Calcium and ischemic injury. N Engl J Med 1986; 314: 1670-6.

[23] Nagamatsu M, Schmelzer JD, Zollman PJ, et al. Ischemic reperfusion causes lipid peroxidation and fiber degeneration. Muscle Nerve 1996; 19: 37-47.

[24] Fu Q, Iwase S, Niimi Y, et al. Age-related influences of leg vein filling and emptying on blood volume redistribution and sympathetic reflex during lower body negative pressure in humans. Jpn J Physiol 2002; 52: 77-84.

[25] Welsch MA, Alomari M, Parish TR, et al. Influence of venous function on exercise tolerance in chronic heart failure. J Cardiopul Rehabil 2002; 22: 321-6.

[26] Opasich C, Pinna GD, Mazza A, et al. Six-minute walking performance in patients with moderate-to-severe heart failure; is it a useful indicator in clinical practice? Eur Heart J 2001; 22: 488-96.

[27] Rolland YM, Cesari M, Miller ME, et al. Reliability of the 400-m usual-pace walk test as an assessment of mobility limitation in older adults. J Am Ger Soc 2004; 52: 972-6.

[28] Steffen TM, Hacker TA, Mollinger L. Age- and gender-related test performance in community-dwelling elderly people: Six-minute walk test, berg balance scale, timed up \& go test, and gait speeds. Phys Ther 2002; 82: 128-37.

[29] Katsiaras A, Newman AB, Kriska A, et al. Skeletal muscle fatigue, strength, and quality in the elderly: the Health ABC Study. J Appl Physiol 2005; 99: 210-6.

[30] Ostchega Y, Dillon CF, Lindle R, et al. Isokinetic leg muscle strength in older Americans and its relationship to a standardized walk test: data from the national health and nutrition examination survey 1999-2000. J Am Ger Soc 2004; 52: 977-82.

[31] Alomari MA, Solomito A, Reyes R, et al. Measurements of vascular function using strain-gauge plethysmography: technical considerations, standardization, and physiological findings. Am J Physiol 2004; 286: H99-H107.

[32] Maiorana A, O'Driscoll G, Cheetham C, et al. The effect of combined aerobic and resistance exercise training on vascular function in type 2 diabetes. J Am Coll Cardiol 2001; 38: 860-6.

[33] Paterson DH, Govindasamy D, Vidmar M, et al. Longitudinal study of determinants of dependence in an elderly population. J Am Ger Soc 2004; 52: 1632-8. 